\title{
Laccase based amperometric biosensor for industrial waste waters: A comparative study on covalent immobilization methods on gold electrode
}

\author{
C. Sarika ${ }^{1}$, K. Rekha ${ }^{2}$, B. NarasimhaMurthy ${ }^{3}$ \\ ${ }^{1 \& 2}$ (Department of Biotechnology Engineering, CMR Institute of Technology, Bangalore 560 037, India) \\ ${ }^{3}$ (Department of Chemistry, CMR Institute of Technology, Bangalore 560 037, India)
}

\begin{abstract}
The behaviour of three different laccase-based amperometric biosensors was studied in view of their use in agricultural or industrial waters polluted by phenolic compounds. Catechol was used as model substrate. Laccase from Trametes versicolor was immobilized directly on gold electrode on one biosensor (type A) by crosslinking with glutaraldehyde while, on the second biosensor (type B), laccase was covalently bound to organothiol layers on gold electrode and finally on the third biosensor (type C) laccase was covalently bound to silanized gold electrode. For each biosensor type, gold electrode of Clark type DO sensor was used for immobilization. The linear range, sensitivity and time stability of each biosensor type were investigated. Among the electrodes tested, type C biosensor was superior to the other types in terms of sensitivity, limit of detection $(L O D)$, response time and operating stability. Biosensor response reached steady state within $3 \mathrm{~min}$ and exhibited maximum activity at $\mathrm{pH7}$. Furthermore, sample application and accuracy of the three types of sensors were also detected.
\end{abstract}

Keywords: Amperometric, Biosensors, Catechol, Enzyme immobilization, Gold electrode.

\section{Introduction}

Phenolic compounds are widespread in nature. They are used in medicine and industries, including wood processing and pesticide production. Phenols are introduced to the environment in variety of ways like wastes from paper manufacturing, agriculture, petrochemical industry, coal processing or as municipal wastes [1]. The degradation products of non ionic surfactants, which are used both in household products and in textile, food, and varnish and paint industries, are another source of phenol derivatives. Many of these compounds are highly toxic, and their determination in low concentrations is an important problem. Due to health and ecological risks caused by long and short term exposure to these phenolic compounds, there is a considerable interest in their measurements in environmental and food samples. In the past decade a variety of analytical methods were proposed for determination of phenol and its derivatives in natural environmental waters and waste waters. The most widely used are gas chromatography [2], high performance liquid chromatography [3] and electrochemical methods [4-5]. These methods offer proper selectivity and detection limits, but, they are not suitable for rapid processing of multiple samples and real-time detection. They involve highly trained operators, time-consuming detection processes, and complex pre-treatment steps. The instruments are sophisticated and expensive. Further, the methods are unsuitable for field studies and in-situ monitoring of samples [6-8].

Therefore, there is an interest in developing simple, sensitive, specific, accurate and portable system such as biosensor for determination of phenolic compounds. Many biosensor research papers have been reported previously for the detection of phenolic compounds based on several types of enzyme such as tyrosinase[9-12], laccase [13-15] and horseradish peroxidase (HRP) [16-17].

Laccase (EC1.10.3.2) is capable of oxidizing phenols by reducing molecular oxygen to water by a multicopper system. The reduction of oxygen to water is accompanied by the oxidation of the phenolic substrate. Laccases have four neighbouring copper atoms which are distributed among different binding sites and classified into three types: copper types 1,2 and 3. Copper type 1 is involved in electron capture and transfer, copper type 2 activates molecular oxygen, while copper type 3 is responsible for oxygen uptake [18].

The substrate range for laccase is fairly wide, including several polyphenolic, aromatic amines, aminophenols and 4-methyl-3-hydroxyanthranilic acid [19-20], and etc. Thus, laccase has found multiple applications in various field including degradation of lignin, wastewater treatment, decolorization and detoxification of textile dyes and biosensor as well [21].

Enzyme immobilization technology is an effective means to improve enzyme stability and to perform its reuse. The sensitivity of analysis and the stability of an enzyme electrode can be improved using new matrices for enzyme immobilization. Enzyme immobilization on electrode surfaces due to physical adsorption, the covalent linking of laccase to the surfaces of carbon materials with bifunctional reagents, incorporation in a gel of bovine serum albumin crosslinked with glutaraldehyde, and incorporation into a polyaniline matrix have 
Laccase based amperometric biosensor for industrial waste waters: A comparative study on ....

been described [22]. The electrodes developed exhibited various characteristics in terms of stability, sensitivity, and analysis time. Laccase has been successfully immobilized on many different types of carriers, such as glass beads, alginate beads, polyaniline matrix, microporous polypropylene hollow fiber membranes, activated carbon, chitosan film and magnetic chitosan microsphere, modified PVDF microfiltration membrane [23-25] as well as mesoporous carbon[26].

In this paper, we will discuss the functioning of three different laccase-based enzyme electrodes, obtained by immobilizing the laccase from Trametes versicolor on gold electrode of Clark type DO sensor via crosslinking and via covalent bond. We used catechol as model substrate. Sensitivities, calibration curves and stability of the three biosensors also were compared. Furthermore, sample application and accuracy of the three types of sensors were also detected.

\subsection{Materials}

\section{Experimental}

Laccase (from Trametes versicolor) having specific activity $10 \mathrm{IU}$ mg-1 was procured from sigma (USA). 3-mercaptopropionic acid (MPA), 1-ethyl-3-(3-dimethyl-aminopropyl)carbodiimide (EDC), Nhydroxysuccinimide (NHS), 3-aminopropyltriethoxysilane (APTES), glutaraldehyde, catechol were from SRL chem. India. All reagents were analytical grade and used as received. Double-distilled water was used throughout the experiments.

\subsection{Apparatus}

A Clark's electrode with an amperometric detection system was used for detection of catechol. An amperometric principle based detector system developed in our laboratory was used to amplify and monitor the signals obtained from enzyme electrode. Clark type of dissolved oxygen electrode was purchased from $\mathrm{M} / \mathrm{S}$ Century Instruments, Chandigarh, India. The Clark-type electrode consists of a Gold (Au) cathode and a reference $\mathrm{Ag} / \mathrm{AgCl}$-electrode. The inter connectivity between working electrode and reference electrode is through the electrolyte. (phosphate buffer saline of $\mathrm{pH} 7$ )

The area of working electrode used here is $0.012 \mathrm{~cm}^{2}$ and the area of reference electrode is $1.64 \mathrm{~cm}^{2}$ as the area of working electrode is much smaller than the reference electrode there was no necessity of using counter electrode. A polarizing potential of $-200 \mathrm{mV}$ was applied to the gold working electrode.

\subsection{Preparation of the laccase-based electrodes}

Three different electrode types, hereafter referred to using the code A, B and C, were prepared. The enzyme immobilization was carried out directly on gold electrode of Clark type DO sensor by crosslinking with glutaraldehyde (A), while it was performed on electrodes B and C using a covalent bond.

\subsubsection{Preparation of electrode $A$}

IIU of enzyme dispersed uniformly on the gold electrode of the DO sensor using micropipette. After drying the enzyme solution for 15 minutes at room temperature, the electrode was exposed to vapour of $25 \%$ glutaraldehyde solution again for 30 minutes at room temperature to make cross-links among the enzymes.

\subsubsection{Preparation of electrode B (laccase covalently bound to organothiol layers on gold electrode of the Clark type DO sensor)}

Self-assembled monolayers of 3-MPA were obtained by immersion of the electrode for $3 \mathrm{~h}$ into $10 \mathrm{mM}$ solution of thiol, buffered to $\mathrm{pH}$ 7. In order to activate the carboxyl groups of the deposited 3-MPA the electrode was immersed in aqueous solution containing $75 \mathrm{mM}$ EDC and $25 \mathrm{mM}$ NHS for 30 minutes, then washed in deionized water for 1 minute and dried. 1IU laccase solution in $0.1 \mathrm{M}$ phosphate buffer $(\mathrm{pH}=7)$ was applied and dispersed uniformly on the electrode using micropipette. Schematic representation of preparing this electrode is given in figure 1. 


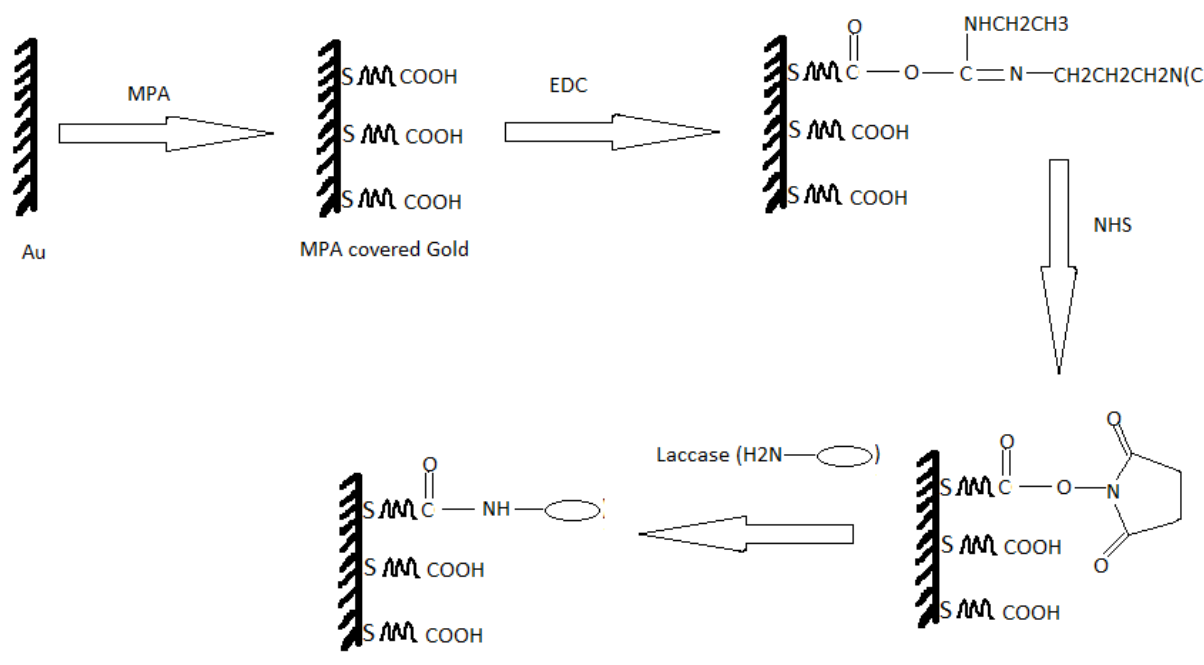

Figure 1: Schematic representation of preparing laccase-based immobilized gold electrode (type B)

\subsubsection{Preparation of electrode C (laccase covalently bound to silanized gold electrode of Clark type DO} sensor)

The gold electrode of the DO sensor was oxidized by $5 \%$ solution of potassium dichromate in $15 \%$ nitric acid $\left(2\right.$ hours, $\left.80^{\circ} \mathrm{C}\right)$ and the electrode was thoroughly rinsed with water and dried. The oxidized electrode was incubated in $2 \%$ aqueous solution $(\mathrm{pH}=7)$ of 3 -aminopropyltriethoxysilane (APTES) at $37^{\circ} \mathrm{C}$ for 1 hour and thoroughly rinsed with water and dried. The silanized electrode was further modified with glutaraldehyde by being exposed to vapor of $25 \%$ glutaraldehyde solution for 1 hour. The glutaraldehyde activated electrode was rinsed with water,dried and $1 \mathrm{IU}$ laccase solution in $0.1 \mathrm{M}$ phosphate buffer $(\mathrm{pH}=7)$ was applied and dispersed uniformly on the electrode using micropipette. After drying the enzyme solution for 30 minutes at room temperature, the electrode was put into vapour of $25 \%$ glutaraldehyde solution again for 30 minutes at room temperature to make further cross-links among the enzymes. The electrode was thoroughly washed with the buffer. Schematic representation of preparing this electrode is given in figure 2.

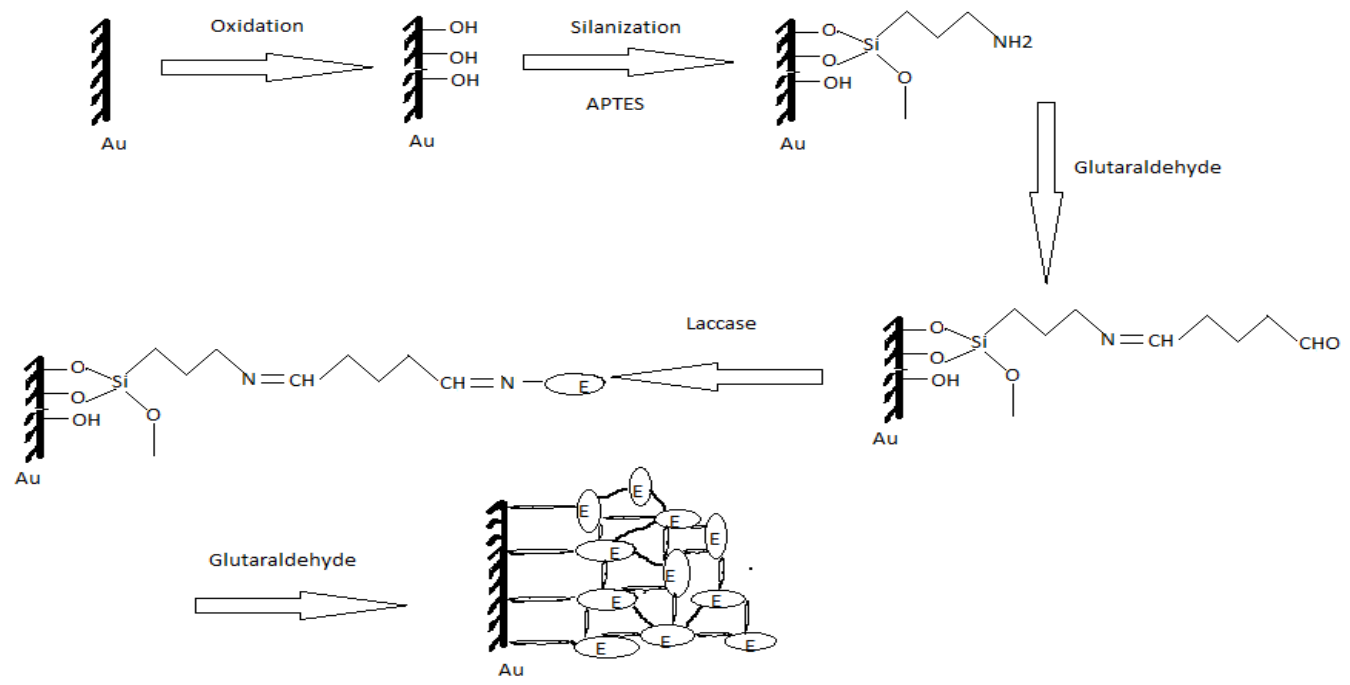

Figure 2: Schematic representation of preparing laccase-based immobilized Au electrode (type C)

\subsection{Construction of biosensor and measurement of response}

After drying for $1 \mathrm{hr}$ the enzyme membrane was washed with phosphate buffer $(\mathrm{pH} 7)$ to remove excess glutaraldehyde. The electrode was immersed in a sample cell containing $5 \mathrm{ml}$ of phosphate buffer saline of $\mathrm{pH} 7$. A schematic diagram of the biosensor is shown in (figure 3). 


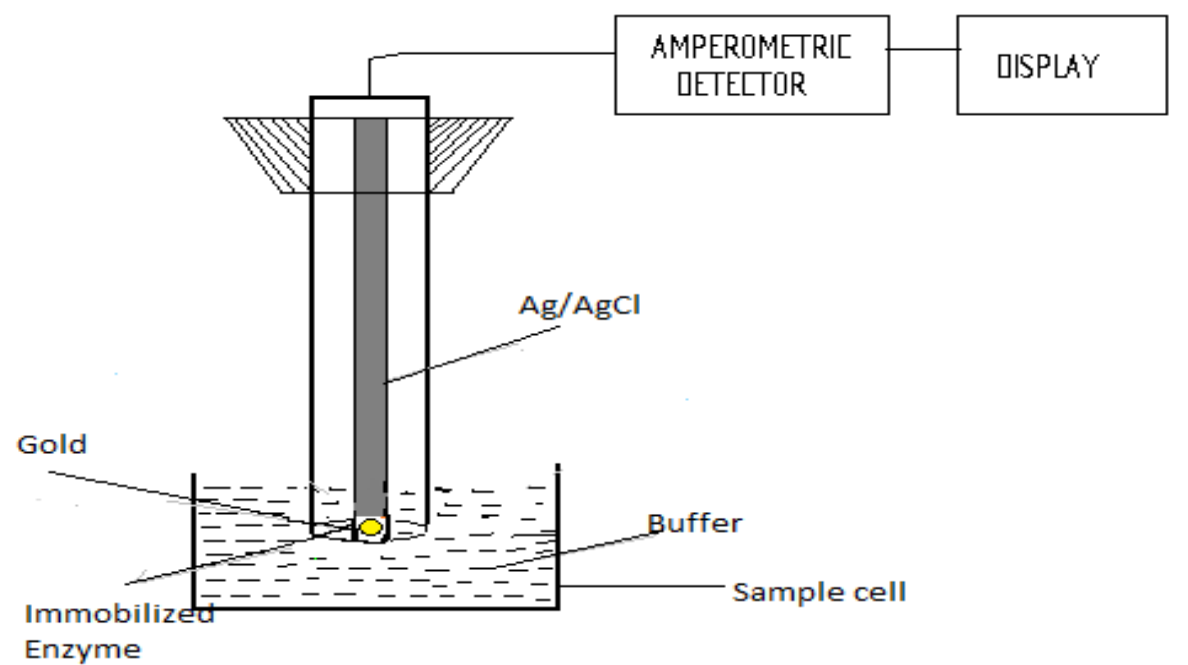

Figure 3: Biosensor configuration

In this work, the principles of the enzymatic reaction are as follows:

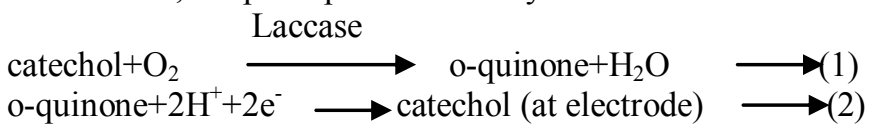

The sample cell was continuously saturated with oxygen using a portable air pump. The probe was connected to the amperometric detector system developed in our laboratory. Then a voltage of $-200 \mathrm{mV}$ was applied. $50 \mu \mathrm{L}$ of standard solutions of catechol of varying concentrations injected into the buffer solution using micropipette under stirring. The response was converted into voltage, amplified and monitored until the system was stable. The variation of the voltage was calculated and this variation is proportional to the substrate concentration. The time taken to reach steady state is 3 minutes. The system provides a 2 -point calibration for quantification of catechol.

\subsection{Operational stability of electrodes}

The operational stability studies of immobilized enzyme electrode were carried out at $28 \pm 2^{\circ} \mathrm{C}$. The electrodes were stored up to by keeping immersed in phosphate buffer of $\mathrm{pH} 7$ and the activity was checked daily by injecting $10 \mu \mathrm{M}$ catechol and the response recorded as drift in voltage.

\subsection{Studies on immobilized enzyme kinetics}

Kinetic parameters for the immobilised laccase catalysed reaction were calculated and compared for the electrodes.

\subsection{Calibration plots and analytical characteristics}

Various analytical features such as linearity range, limit of detection, correlation coefficient $\left(\mathrm{R}^{2}\right)$, and sensitivity were studied for the three electrodes.

\subsection{Sample application}

The laccase based biosensors (type A, B and C) were applied in synthetic waste water samples. Validations of the three types of biosensors were carried out by comparing the results obtained from the test biosensors with that of HPLC. A Schimadzu model High Performance liquid chromatograph equipped with a LC 20AD model pump and an injector was used in the present study, and the column effluents were monitored at $280 \mathrm{~nm}$. Peak areas were determined using LC solution software. The flow rate was $1 \mathrm{ml} / \mathrm{min}$. A $250 \mathrm{X} 4.6 \mathrm{~mm}$ Luna $5 \mathrm{u} \mathrm{C18}$ column was used. Methanol/water mixture was used as the mobile phase.

\section{Results And Discussion}

\subsection{Optimum pH for the laccase catalysed reaction for the three electrodes}

Since an enzyme reaction is strongly dependent on the $\mathrm{pH}$ of the solution, especially when the catalyst is immobilized, the biosensor response was studied at different values of the $\mathrm{pH}$ in the range from 4 to 8 . In Fig. 4 , the results of this investigation are reported for each of the three biosensor types. The catechol concentration was $10 \mu \mathrm{M}$ and the temperature $28^{\circ} \mathrm{C}$. The results in the figure clearly show that the best response for each of the biosensor types occurs at $\mathrm{pH} 7$. 


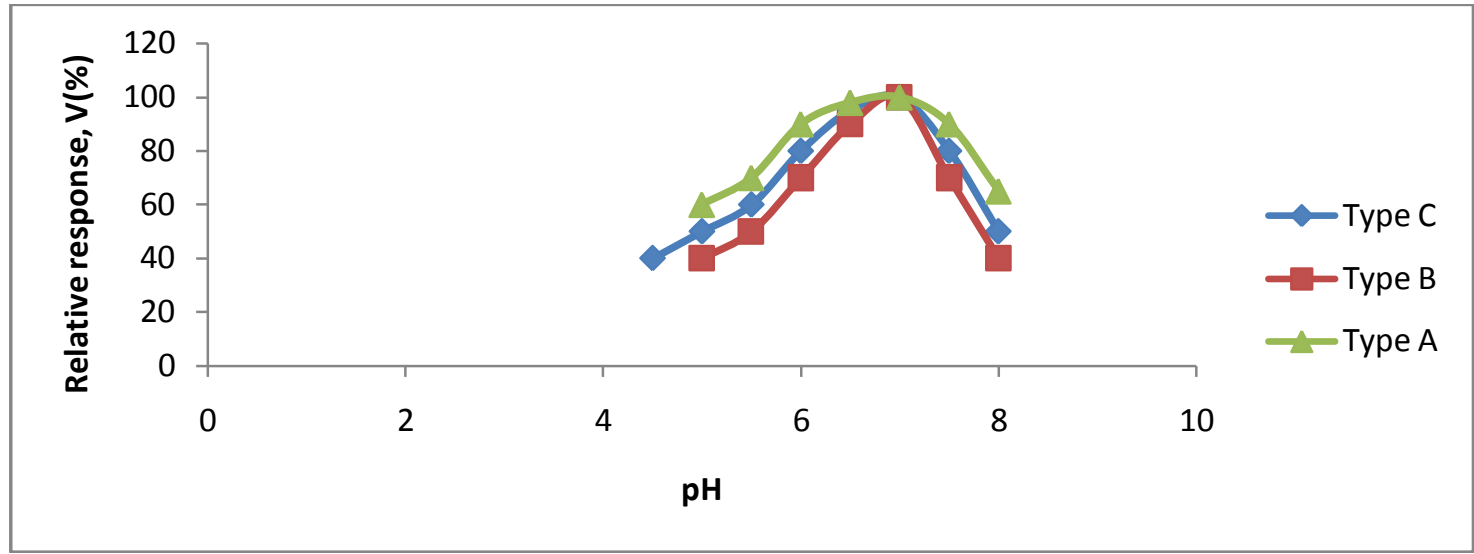

Figure 4: Relative $\mathrm{V}$ values as a function of $\mathrm{pH}$.

\subsection{Calibration plot, different analytical characteristics and operational stability}

Once established that the optimum value of the peak current for our biosensors occurs at $\mathrm{pH}$ 7.0, further experiments were conducted under these conditions in order to obtain calibration curves for each biosensor type. The results of the experiment are shown in Figs. 5-7, where the responses are reported as a function of catechol concentration. Fig. 5 refers to biosensor A, Fig. 6 to biosensor B, and Fig. 7 to biosensor C. Sensitivities are the slopes of the calibration curves.

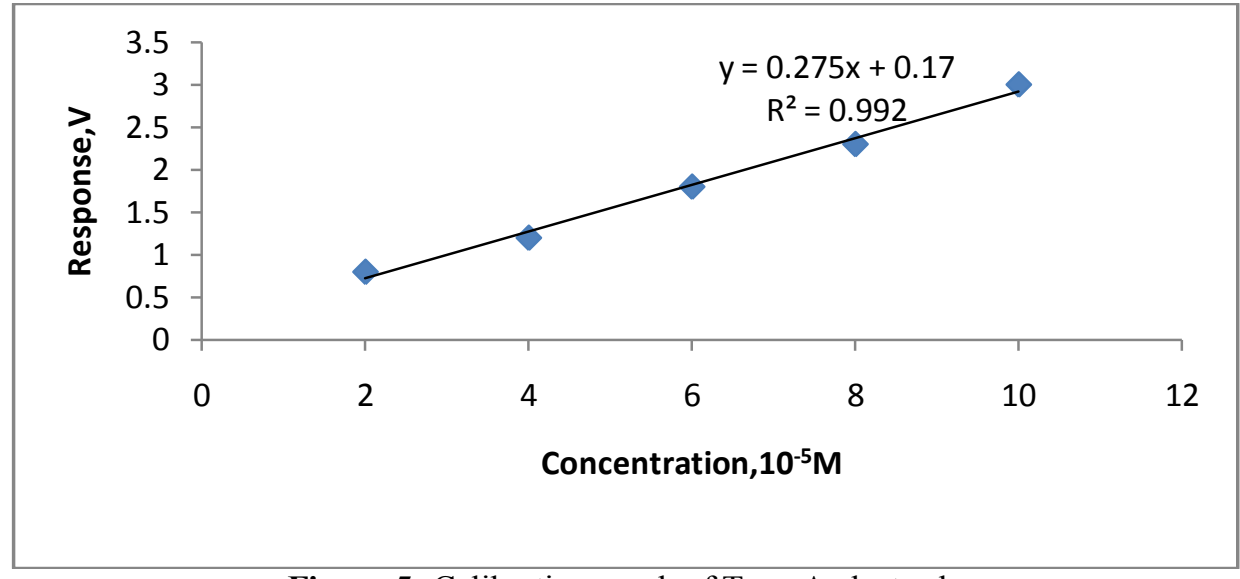

Figure 5: Calibration graph of Type A electrode

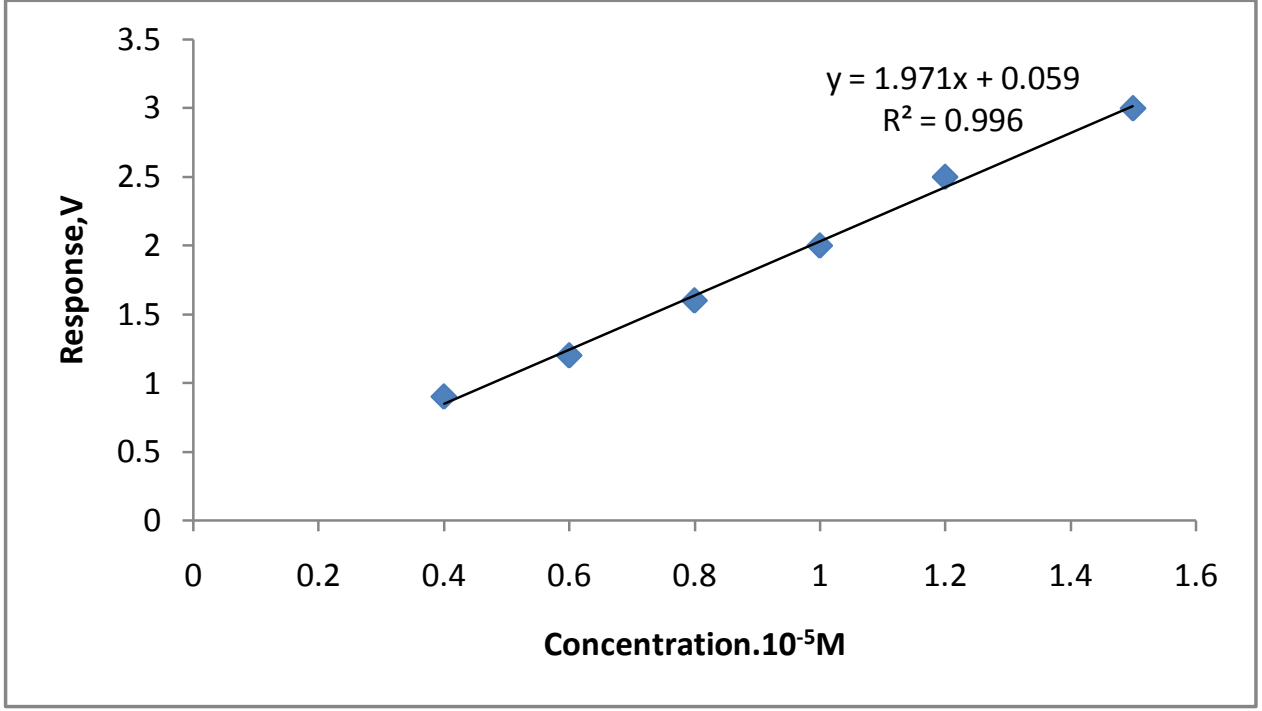

Figure 6: Calibration graph of Type B electrode 


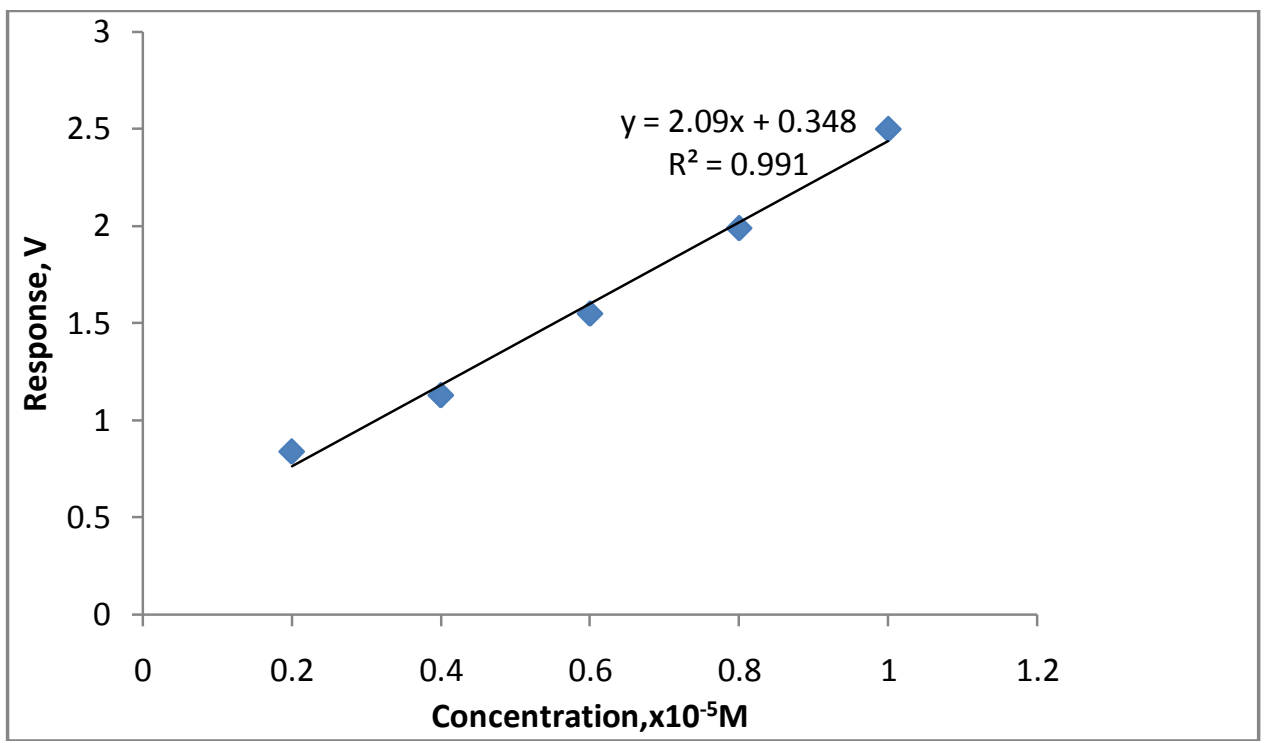

Figure 7: Calibration graph of Type $\mathrm{C}$ electrode

Table 1 summarises the characteristics of the calibration plots obtained for the three laccase electrodes under the optimized working conditions. The data show that sensitivities are higher when the laccase is covalently bound to the electrode in comparison to the value obtained with the type A electrode. The opposite is true when the extension of the linear range is considered. Similar results were obtained using another system [27].

Sensitivity of the biosensors developed with catechol as model substrate was found to be in the order: Type C > Type B > Type A. Therefore, Type C electrode was found to be the best in terms of sensitivity, LOD, response time and operating stability.

The covalent immobilization could make the redox cycle of the substrate to take place on the surface very closely and minimize the diffusional resistance between electrode surface and enzyme layer to give a fast response $[28,29]$. The very stable response of the sensor can be related to the good reversibility of the substrate, stable enzyme loading due to covalent immobilization, unblocked channels in enzyme layers for mass transport, and so on. Although the exact reason for the improved sensitivity of the sensor is not fully understood, several effects may be considered: the better affinity of the enzyme for the substrate, the increased catalytic rate of the enzyme for the substrate, and the better mobility of the substrate in the enzyme layer [30, 31]. The relatively low sensitivity in high substrate concentrations can be ascribed to the saturation of the enzyme active site by the substrate. The variations in sensitivity can be mainly attributed to the substrate specificity of the enzyme from different sources and to the different immobilization methods.

The sensor signal of the laccase covalently immobilized on gold electrode via silanization is very stable and rather reproducible. The response time is $3 \mathrm{~min}$. The stability of the sensor is outstanding, which is as long as 30 days (retaining $50 \%$ of initial activity). The detection limit is about $0.06 \times 10^{-5} \mathrm{M}$, and the linear range is $0.2-1 \times 10^{5} \mathrm{M}$. The reasons for most performance of the sensor prepared by silanization might be resulted from the flexibility and the higher surface density of the linker, 3-aminopropyltriethoxysilane.

The repeatability of the biosensors is checked by the determination of $50 \mu \mathrm{mol} / \mathrm{L}$ catechol in 10 replicates. As exhibited in Table 1, the relative standard deviation ( $\mathrm{RSD} \leq 4 \%)$ of the results indicates the reliable repeatability, accuracy and reusability of the biosensors.

Table 1: Analytical characteristics of laccase based biosensors

\begin{tabular}{|l|l|l|l|l|l|l|l|l|}
\hline $\begin{array}{l}\text { Biosensor } \\
\text { type }\end{array}$ & $\begin{array}{l}\text { Sensitivity } \\
\mathrm{V} / \mathrm{x} 10^{-5} \mathrm{M}\end{array}$ & $\begin{array}{l}\text { Linearity range } \\
\left(\mathrm{x} 10^{-5} \mathrm{M}\right)\end{array}$ & $\begin{array}{l}\text { LOD } \\
\left(\mathrm{x} 10^{-5} \mathrm{M}\right)\end{array}$ & $\begin{array}{l}\text { Response } \\
\text { time(min.) }\end{array}$ & $\mathrm{R}^{2}$ & $\begin{array}{l}\text { Stability } \\
\text { days }\end{array}$ & $\begin{array}{l}\text { Half life } \\
(\mathrm{no} . \\
\text { analysis })\end{array}$ \\
\hline $\mathrm{A}$ & 0.275 & $1-10$ & 0.6 & 3 & 0.992 & 10 & 50 & $\begin{array}{l}\% \mathrm{RSD} \\
(\mathrm{n}=10)\end{array}$ \\
\hline $\mathrm{B}$ & 1.97 & $0.4-1.5$ & 0.07 & 4 & 0.996 & 20 & 110 & 4 \\
\hline $\mathrm{C}$ & 2.09 & $0.2-1$ & 0.06 & 3 & 0.991 & 30 & 150 & 3.01 \\
\hline
\end{tabular}

\subsection{Immobilized enzyme kinetics}

Immobilized enzyme kinetics was studied using catechol as model substrate. Apparent MichaelisMenten constants ( $\mathrm{K}_{\mathrm{m}}$ app.), and the maximum rate of reaction (Vmax) were calculated from the corresponding Lineweaver-Burk plots as shown in (Table 3). 
As theoretically predicted, the sensitivity of the biosensors for each phenolic compound is higher as the corresponding $\mathrm{Km}$, app is lower and the $\mathrm{Vm}$ value (which is proportional to the catalytic constant for the conversion of the enzyme-substrate complex into the product plus the enzyme) is higher. Thus, the ratio $\mathrm{Vm} / \mathrm{Km}$, app, the catalytic efficiency, gives a prior indication of the substrates sensitivity trend. Silanization method displays a greater affinity towards catechol when compared to other methods of immobilization. Hydrophobic interactions are considered as the single most important factor in stabilization of the enzyme structure. Therefore strengthening of these interactions should impart structural rigidity to the enzyme molecules. Silane has been used for the surface modification of solid supports for the immobilization of enzymes, wherein the non-reactive groups in silane such as alkyls provide hydrophobicity and render the surface positively charged [32].

It is therefore evident that, in order to design laccase-based biosensors for the determination of phenolic compounds one must adapt the immobilization methods on the basis of the interest in having high sensitivity.

Table 3: Kinetic parameters for the laccase catalysed reaction using enzyme electrode employing various methods of immobilisation with catechol as substrate.

\begin{tabular}{|l|l|l|l|}
\hline Immobilization & Vmax (V) & Km,app. $\left(x 10^{-5} \mathrm{M}\right)$ & $\begin{array}{l}\text { Vmax./Km,app. } \\
\left(\mathrm{V} / \mathrm{x} 10^{-5} \mathrm{M}\right)\end{array}$ \\
\hline Type A & 4.0 & 7.00 & 0.5714 \\
\hline Type B & & & \\
\hline Type C & 4.25 & 1.05 & 4.0476 \\
\hline
\end{tabular}

\subsection{Sample application.}

Validation of the test biosensors were successfully performed by comparing the results with conventional HPLC. Synthetic waste water samples prepared with known amount of catechol were used as stock substrate solution with different dilution by working buffer and $50 \mu \mathrm{l}$ of waste water sample was added to the reaction cell after equilibration had occurred and then the change in current was measured. The signals obtained from these samples were found to be very similar with that of the reference compound solutions having the same concentration. Good correlation was observed between results obtained with the test biosensor and those with HPLC (Table 4).

Table 4: Synthetic waste water sample analysis using test biosensors

\begin{tabular}{|c|c|c|c|c|c|}
\hline \multirow[t]{2}{*}{ Sample } & \multirow{2}{*}{$\begin{array}{l}\text { Catechol } \\
\text { concentration in } \\
\text { waste water sample } \\
(\mu \mathrm{M})\end{array}$} & \multicolumn{4}{|c|}{ Detected amount $(\mu \mathrm{M})$} \\
\hline & & Type A & Type B & Type C & HPLC \\
\hline 1 & 10 & $9.89 \pm 0.03$ & $9.93 \pm 0.05$ & $10.10 \pm 0.018$ & $10.01 \pm 0.026$ \\
\hline 2 & 8 & $7.93 \pm 0.039$ & $8.02 \pm 0.012$ & $7.98 \pm 0.039$ & $8.03 \pm 0.027$ \\
\hline
\end{tabular}

Note: Results are expressed as \pm S.D., $n=5$

\section{Conclusions}

It has been demonstrated that it is possible to modulate the electrical response of laccase-based biosensors by using different immobilization methods directly on gold electrode of Clark type DO sensor. Laccase immobilization using covalent bonds ensures higher sensitivities with respect to immobilization obtained by crosslinking method directly on gold. This provides clear indications for the design of biosensors obtained by covalent enzyme immobilization, provided that the time stability is interesting. The sensor signal of the laccase covalently immobilized on gold electrode of DO sensor via silanization is very stable and rather reproducible. This electrode was found to be the best in terms of sensitivity, LOD, response time and operating stability. Therefore, the system could be easily applied for the screening of phenolic compounds in industrial effluents.

\section{Acknowledgments}

Financial support from Department of Science and Technology (DST), Govt. Of India under the project [DST/TSG/ME/2009/65] is gratefully acknowledged.

\section{References}

[1]. J. Adamski, P. Nowak and J. Kochana, Simple sensor for determination of phenol and its derivatives in water based on enzyme tyrosinase. ElectrochimicaActa 55(7), 2010, 2363-2367.

[2]. J.A. Padilla-Sanchez , P. Plaza-Bolanos, R. Romero-Gonzalez, N. Barco-Bonilla, J.L. Martinez-Vidal and A. Garrido-Frenich, Simultaneous analysis of chlorophenols, alkylphenols, nitrophenols and cresols in wastewater effluents, using solid phase extraction and further determination by gas chromatography-tandem mass spectrometry, Talanta, 85(5), 2011, 2397-2404. 
[3]. T. Tanigawa, Y. Watabe, T. Kubo and K. Hosoya, Determination of bisphenol A with effective pretreatment medium using automated column-switching HPLC with fluorescence detection, Journal of Separation Science, 34(20), 2011, $2840-2846$.

[4]. T. Jing, H. Xia, J. Niu, Y. Zhou, Q. Dai, Q. Hao,Y. Zhou and S. Mei, Determination of trace 2,4-dinitrophenol in surface water samples based on hydrophilic molecularly imprinted polymers/nickel fiber electrode, Biosensors and Bioelectronics, 26(11), 2011, 4450-4456.

[5]. L. Vidal, A. Chisvert, A. Canals, E. Psillakis, A. Lapkin, F. Acosta, K.J. Edler, JA. Holdaway and F. Marken, Chemically surfacemodified carbon nanoparticle carrier for phenolic pollutants: extraction and electrochemical determination of benzophenone-3 and triclosan, Analytica Chimica Act, 616(1), 2008, 28-35.

[6]. H. S. Yin, Y. Zhou and S.-Y. Ai, Preparation and Characteristic of Cobalt Phthalocyanine Modified Carbon Paste Electrode for Bisphenol A Detection, Journal of Electroanalytical Chemistry, 626(1-2), 2009, 80-88.

[7]. C. R. Suri, R. Boro, Y. Nangia, S. Gandhi, P. Sharma, N. Wangoo, K. Rajesh and G. S. Shekhawat, Immunoanalytical Techniques for Analyzing Pesticides in the Environment, Trends in Analytical Chemistry, 28(1), 2009, 29-39.

[8]. A. F. Le Blanc, C .Albrecht, T. Bonn, P. Fechner, G. Proll, F. Proll, M. Carlquist and G. Gauglitz, A Novel Analytical Tool for Quantification of Estrogenicity in River Water Based on Fluorescence Labelled Estrogen Receptor, Analytical and Bioanalytical Chemistry, 395(6), 2009, 1769-1776.

[9]. T. Mai Anh, S. V. Dzyadevych, A. P. Soldatkin, N. DucChien, N. Jaffrezic-Renault and J.-M. Chovelon, Development of Tyrosinase Biosensor Based on pH-Sensitive Field-Effect Transistors for Phenols Determination in Water Solutions, Talanta, 56(4), 2002, 627- 634 .

[10]. L. C. Clark Jr. and C. Lyons, Electrode Systems for Continuous Monitoring in Cardiovascular Surgery, Annals of the New York Academy of Sciences, 102, 1962, 29-45.

[11]. A. M. Girelli, E. Mattei, A. Messina and D. Papaleo, Immobilization of Mushroom Tyrosinase on Controlled Pore Glass: Effect of Chemical Modification, Sensors and Actuators B, 125(1), 2007, 48-54.

[12]. S. Nadifiyine, M. Haddam, J. Mandli, S. Chadel, C. C. Blanchard, J. L. Marty and A. Amine, Amperometric Biosensor Based on Tyrosinase Immobilized on to a Carbon Black Paste Electrode for Phenol Determination in Olive Oil, Analytical Letters, 46(17), 2013, 2705-2726.

[13]. T. Shimomura, TetsujiItoh, T. Sumiya, Taka-aki Hanaoka, F. Mizukami and M. Ono, Amperometric detection of phenolic compounds with enzyme immobilized in mesoporous silica prepared by electrophoretic deposition, Sensors \& Actuators: B.Chemical, 153(2), 2011, 361-368.

[14]. R.S. Freire, N. Durán, J. Wang and L.T. Kubota, Laccase-based screen printed electrode for amperometric detection of phenolic compounds, Analytical Letters, 35(1), 2002, 29-38.

[15]. A. I. Yaropolov, A. N. Kharybin, J. Emnéus, G. MarkoVarga and L. Gorton, Flow Injection Analysis of Phenols at a Graphite Electrode Modified with Co-Immobilized Laccase and Tyrosinase, AnalyticaChimicaActa, 308(1), 1995, 137-144.

[16]. S. Imabayashi, Y. T. Kong and M. Watanabe, Amperometric Biosensor for Polyphenol Based on Horseradish Peroxidase Immobilized on Gold Electrodes, Electroanalysis, 13(5), 2001, 408-412.

[17]. S. Korkut, B. Keskinler and E. Erhan, An Amperometric Biosensor Based on Multiwalled Carbon Nanotube-Poly (Pyrrole)Horseradish Peroxidase Nanobiocomposite Film for Determination of Phenol Derivatives, Talanta, 76(5), $2008,1147-1152$.

[18]. L Setti, S Giuliani, G Spinozzi and P.G. Pifferi, LaccaseCatalyzed- oxidative Coupling of 3-methyl 2-benzothiazolinone Hydrazone and Methoxyphenols, Enzyme and Microbial Technology, 25(3-5), 1999, 285-289.

[19]. J Osiadacz, A J H Al-Adhami, D Bajraszewska, P. Fischer and W. Peczynska-Czoch, On the Use of Trametes Versicolor Laccase for the Conversion of 4-methyl-3-hydroxyanthranilic Acid to ActinocinChromophore, Journal of Biotechnology,72(1-2), 1999, 141149 .

[20]. E Srebotnik and K E Hammel, Degradation of Nonphenolic Lignin by the Laccase: 1-hydroxybenzotriazole System, Journal ofBiotechnology, 81(2-3), 2000, 179-188.

[21]. C. Mousty, L. Vieille and S. Cosnier, Laccase Immobilization in Redox Active Layered Double Hydroxides: a Reagentless AmperometricBiosensor, Biosensors and Bioelectronics, 22(8), 2007, 1733-1738.

[22]. R.S. Freire, N. Duran, and L.T. Kubota, Effects of fungal laccase immobilization procedures for the development of a biosensor for phenol compounds, Talanta, 54(4), 2001, 681-686.

[23]. A Domínguez, J Gómez, M Lorenzo and A. Sanroman, Enhanced Production of Laccase Activity by Trametes Versicolor Immobilized into Alginate Beads by the Addition of Different Inducers, World Journal of Microbiology and Biotechnology, 23(3), 2007, 367-373.

[24]. S Timur, N Pazarlığlu, R Pilloton and A. Telefonzu, Thick Film Sensors Based on Laccases from Different Sources Immobilized in PolyanilineMatrix, Sensors and Actuators B:Chemical, 97(1), 2004, 132-136.

[25]. D. S. Jiang, S. Y. Long, J. Huang, Hai-Yan Xiao and Ju-Ying Zhou, Immobilization of Pycnoporus Sanguineus Laccase on Magnetic Chitosan Microspheres, Biochemical Engineering Journal, 25(1), 2005, 15-23.

[26]. K. C. W. Wu and Y. Yamauchi, Controlling physical features of mesoporous silica nanoparticles (MSNs) for emerging applications, Journal of Material Chemistry, 22(4), 2012, 1251-1256.

[27]. M. Portaccio, M. ElMasry, S. Rossi, N. Diana, A. De Maio, V. Grano, N.M. Lepore, P. Travascio, U. Bencivenga, N. Pagliuca, D.G. Mita, An amperometric sensor employing glucose oxidase immobilized on nylon membranes with different pore diameter and grafted with different monomers, Journal of Molecular Catalysis B: Enzymatic, 18(1-3), 2002, 49-67.

[28]. T. Wasa, K. Akimoto, T. Yao and S. Murao, Development of laccase membrane electrode by using carbon electrode impregnated with epoxy resin and its response characteristics, Nippon Kagaku Kaishi, 57(9), 1984, 1398-1403.

[29]. W. Jin, F. Bier, U. Wollenberge and F. Scheller, Construction and characterization of multi-layer-enzyme electrode-Covalent binding of quinoprotein glucose dehydrogenase onto gold electrodes, Biosensors and Bioelectronics, 10(9-10), 1995, 823-829.

[30]. F. Lisdat, U. Wollenberger, A. Markower, H. Hortnagl, D. Pfeiffer and F.W. Scheller, Catecholamine detection using enzymatic amplification, Biosensors and Bioelectronics, 12(12), 1997, 1199-1211.

[31]. U. Wollenberger and B. Neumann, Quinoprotein glucose dehydrogenase modified carbon paste electrode for detection of phenolic compounds, Electroanalysis, 9(5), 1997, 366-371.

[32]. J.J. Cras, C. Tailt, D.A. Nivens and F.S. Liler, Comparison of chemical cleaning methods of glass in preparation for silanization. Biosensors and Bioelectronics, 14, 1999, 683-688. 